\title{
An Integrated Methodology using Linguistic PROMETHEE and Maximum Deviation Method for Third-party Logistics Supplier Selection
}

\author{
Chen-Tung Chen, Ping-Feng Pai, Wei-Zhan Hung \\ Department of Information Management, National United University, Miao-Li, Taiwan \\ E-mail:ctchen@nuu.edu.tw \\ Department of Information Management, National Chi Nan University, Nan-Tou, Taiwan \\ paipf@ncnu.edu.tw \\ Department of International Business Studies, National Chi Nan University, Nan-Tou, Taiwan \\ steady_2006@hotmail.com
}

\begin{abstract}
The purpose of this paper is to present a framework and a suitable method for selecting the best logistics supplier. In general, many quantitative and qualitative criteria should be considered simultaneously for making the decision of logistics supplier selection. The information about judging the performance of logistics suppliers will come from customers' opinions, experts' opinions and the operational data in the real environment. Under this situation, the selection problem of logistic suppliers will be the uncertainties and fuzziness problems in the decision making process. Therefore, we combined the linguistic PROMETHEE method with maximum deviation method to determine the ranking order of logistics suppliers. And then, an example is implemented to demonstrate the practicability of the proposed method. Finally, some conclusions are discussed at the end of this paper.
\end{abstract}

Keywords: Linguistic PROMETHEE, Maximum deviation method, Multi-criteria decision making, Logistic suppliers.

Received: 14-01-2010; Accepted: 25-05-2010

\section{Introduction}

In the global environment, the degree of the competition among companies becomes more and more intensive. The characteristics of competitive environment are such as thin profit margins, high consumer expectations for quality products, shorter life cycles, shorter lead-times, faster dissemination and proliferation of information ${ }^{1}$. So, companies are forced to take advantage of any opportunity to optimize their business processes. Companies have understood that they must focus on their core competence. In order to increase the competitiveness, they outsourced some of their non-core activities to other companies that have made these particular activities into their core competence ${ }^{2-3}$. Logistics services are one of business activities can be outsourced. The main advantage of outsourcing services is that the third-party logistics (3PLs) allow companies to get into a new business, a new market, or a reverse logistics program without interrupting forward flows; in addition, logistics costs can be greatly reduced ${ }^{4-6}$. However, the behavior of third- party logistics supplier will indirectly affect the quality of product and influence image of the company. Therefore, selecting the suitable third-party logistics supplier is important issue for each company.

In order to choose the suitable supplier, some methods are presented for the logistics supplier selection such as analytic hierarchy process(AHP) $)^{7-8}$, analytic network process (ANP) $)^{9-10}$, fuzzy Technique for Order Preference by Similarity to Ideal Solution (fuzzy TOPSIS) approach $^{11}$, scoring method and fuzzy expert system ${ }^{12}$, data envelopment analysis (DEA) ${ }^{13-14}$, Linear programming (LP) ${ }^{15-16}$, Integer linear programming ${ }^{17-18}$, Multi-objective programming ${ }^{19-20}$, Genetic algorithm $(\mathrm{GA})^{21}$, hybrid decision support system ${ }^{22}$, principal component analysis (PCA) and factor analysis (FA) ${ }^{23}$.

Many factors will influence the decision-making of third-party logistics suppliers' selection. In the past, many literatures proposed various model to deal with the selection problem of logistics suppliers. Cao et al. ${ }^{1}$ presented a two-stage method based on Borda function theory (BF) and Gray Rational Analysis (GRA) for 
logistic outsourcing decision-making. In their study, they considered ten factors to select the suitable logistics suppliers. Kannan et al. ${ }^{4}$ put forward a hybrid method by combining Interpretive Structural Modeling (ISM) with fuzzy TOPSIS for the selection of third-party reverse logistics provider (3PRLP). They considered seven influence factors to evaluate and select among 15 reverse logistics providers. Chan et al. ${ }^{8}$ identified 15 important decision criteria including cost, quality, service performance and supplier's profile such as the risk factors involved in the selection of global supplier in the current business scenario and apply fuzzy extended analytic hierarchy process (FEAHP) to evaluate the global suppliers. Chen et al. ${ }^{11}$ presented a fuzzy approach to deal with the problem of supplier evaluation and selection in supply chain management. In their paper, five major factors are used to select the suitable supplier. Boran et al. ${ }^{24}$ utilized intuitionistic fuzzy weighted averaging (IFWA) operator to aggregate individual opinions of decision makers for rating the importance of criteria and alternatives. They presented a group decision making method based on TOPSIS by using intuitionistic fuzzy set to deal with supplier evaluation problem. There are four major criteria are considered for supplier selection such as price, on-time delivers, relationship closeness and product quality. Jharkharia et al..$^{25}$ considered hierarchy structure of criteria and used analytic network process (ANP) to select logistics service provider. Wang et al. ${ }^{26}$ used fuzzy hierarchical TOPSIS for supplier selection. There are five factors are considered in their study. Yin et al. ${ }^{27}$ presented a decision model based on grey situation and information entropy for third-party logistics suppliers selection. Information entropy indicator is applied to determine the objective weight, and grey situation decision is used to choose the best supplier. Ten influenced factors are considered in this proposed model. Tang $^{28}$ considered 5 main criteria including objective logistics capacity, service quality, management efficiency level, development potential and price advantage. He presented a support vector machine (SVM) method for assessment of the capacity logistics supplier. Some criteria are collected from the past literatures and shown in Table 1. According to the Table 1, six criteria are usually used to select the suitable third-party logistics suppliers such as price, service quality, on-time deliveries, relationship closeness, financial structure, information technology.

A few of supplier selection literatures deal with conflicting criteria which exist in logistics supplier selection problem. For example, high-level logistics services mean high service price. Service quality and outsource cost are conflicting criteria and we must make a trade-off between them.

The 2-tuple linguistic representation model is based on the concept of symbolic translation ${ }^{29-30}$. Decision makers can apply 2-tuple linguistic variables to express their subjective opinions and obtain the final evaluation result with appropriate linguistic variable. It is an effective method to reduce the mistakes of information translation and avoid information loss through computing with words ${ }^{31}$.

PROMETHEE (Preference Ranking Organization Method for Enrichment Evaluation) is a multi-criteria decision making method developed by Brans ${ }^{32}$. It is well adapted to problems where a finite number of alternative actions are to be ranked considering several, sometimes conflicting, criteria ${ }^{33}$. There are six basic types of preference function in PROMETHEE method, so experts can select suitable function flexibly according to the requirement of competition condition in the same industry with respect to each criterion by PROMETHEE method ${ }^{34}$.

The maximizing deviation method is proposed by Wang $^{35}$ to compute the weight of each criterion in multiple attribute decision making (MADM) problems with numerical information. If some criterion makes the performance values among all the alternatives have obvious differences, such a criterion plays a more important role in choosing the best alternative. The distinguish ability and objectivity of the maximizing deviation method is better than AHP which is based on subjective opinions of experts ${ }^{36}$.

In this paper, qualitative and quantitative criteria are considered simultaneously for selecting the suitable logistics supplier. We use 2-tuple linguistic valuable to express experts' and customers' subjective opinions and collect crisp value about the performance of logistics supplier respect to quantitative criteria. In order to compare and calculate rationally, all of the quantitative and qualitative information will transfer to the same level of 2-tuple linguistic valuable. And then, a new linguistic 
decision-making is presented by combining linguistic PROMETHEE with maximum deviation method to determine the ranking order of logistic suppliers.

This paper is organized as follows. In section 2, we collected the criteria of logistics supplier selection from the past literatures. In section 3, we presented the context of the 2-tuple linguistic variable. In section 4, we discussed the concept and formula of the maximizing deviation method. In section 5, we described the detail of the proposed method, and then an example is implemented to demonstrate the procedure for the proposed method at the section 6 . Finally, conclusions are discussed at the end of this paper.

\section{The 2-Tuple Linguistic Representation}

\subsection{The fuzzy set and triangular fuzzy number}

The fuzzy set theory is first introduced by Zadeh in $1965^{37}$. The fuzzy set theory is a very feasible method to handle the imprecise and uncertain information in a real world $^{38}$. Especially, it is more suitable for subjective judgment and qualitative assessment in the evaluation processes of decision making than other classical evaluation methods applying crisp values ${ }^{39-40}$.

A positive triangular fuzzy number (PTFN) $\widetilde{T}$ can be defined as $\widetilde{T}=(l, m, u)$, where $l \leq m \leq u$ and $l>0$, shown in Fig.1. The membership function $\mu_{\widetilde{T}}(x)$ of positive triangular fuzzy number (PTFN) $\widetilde{T}$ is defined $\mathrm{as}^{41}$

$$
\mu_{\widetilde{T}}(x)=\left\{\begin{array}{l}
\frac{x-l}{m-l}, l<x<m \\
\frac{u-x}{u-m}, m<x<u \\
0, \text { otherwise }
\end{array}\right.
$$

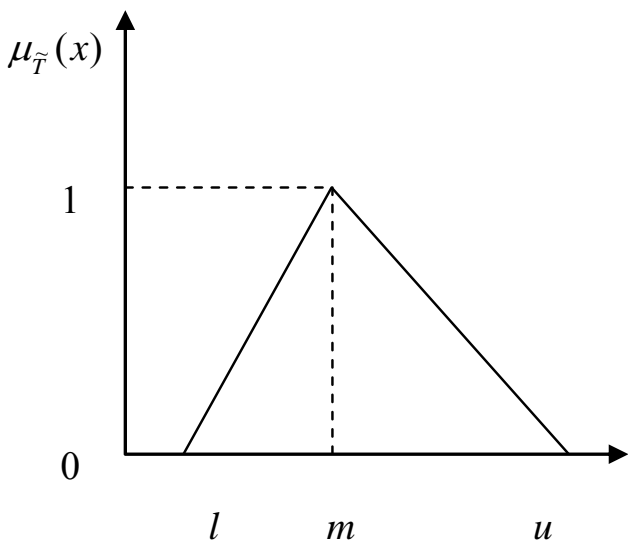

Fig. 1. Triangular fuzzy number $\widetilde{T}$.

A linguistic variable is a variable whose values are expressed in linguistic terms. In other words, variable whose values are not numbers but words or sentences in a nature or artificial language ${ }^{42-43}$. For example, "quality" is a linguistic variable whose values are very low, low, medium, high, very high, etc. These linguistic values can also be represented by fuzzy numbers. There are two advantages for using triangular fuzzy number to express linguistic variable ${ }^{44}$. First, it is a rational and simple method to use triangular fuzzy number to express customers' opinions. Second, it is easy to do fuzzy arithmetic when using triangular fuzzy number to express the linguistic variable. It is suitable to represent the degree of subjective judgment in qualitative aspect than crisp value.

\subsection{The 2-tuple linguistic variable}

Let $S=\left\{s_{0}, s_{1}, s_{2}, \ldots, s_{g}\right\}$ be a finite and totally ordered linguistic term set. The number of linguistic term is $\mathrm{g}+1$ in set $\mathrm{S}$. A 2-tuple linguistic variable can be expressed as $\left(s_{a}, \alpha_{a}\right)$, where $s_{a}$ is the a-th linguistic term in $\mathrm{S}$ and $\alpha_{a}$ is a numerical value representing the difference between calculated linguistic term and the closest index label in the initial linguistic term set. The concept of symbolic translation function is presented to translate crisp value into a 2 -tuple linguistic variable ${ }^{45}$. The generalized translation function can be represented $\mathrm{as}^{46}$ 


$$
\begin{gathered}
\Delta:[0,1] \rightarrow S \times\left[-\frac{1}{2 g}, \frac{1}{2 g}\right) \\
\Delta(\beta)=\left(s_{a}, \alpha_{a}\right)
\end{gathered}
$$

Where $\beta \in[0,1], a=\operatorname{round}(\beta \times g), \alpha_{a}=\beta-\frac{a}{g}$, and $\alpha_{a} \in\left[-\frac{1}{2 g}, \frac{1}{2 g}\right)$.

A reverse function $\Delta^{-1}$ is defined to return an equivalent numerical value $\beta$ from 2-tuple linguistic information $\left(s_{a}, \alpha_{a}\right)$. According to the symbolic translation, an equivalent numerical value $\beta$ is obtained as follow $^{46}$

$$
\Delta^{-1}\left(s_{a}, \alpha_{a}\right)=\frac{a}{g}+\alpha_{a}=\beta
$$

Let $\mathrm{x}=\left\{\left(\mathrm{r}_{1}, \alpha_{1}\right),\left(\mathrm{r}_{2}, \alpha_{2}\right), \ldots,\left(\mathrm{r}_{\mathrm{n}}, \alpha_{\mathrm{n}}\right)\right\}$ be a 2-tuple linguistic variable set. The arithmetic mean $\bar{X}$ is computed as ${ }^{47}$

$$
\bar{X}=\Delta\left(\frac{1}{n} \sum_{a=1}^{n} \Delta^{-1}\left(r_{a}, \alpha_{a}\right)\right)=\left(s_{m}, \alpha_{m}\right)
$$

where $\mathrm{n}$ is the amount of 2-tuple linguistic variable. The $\left(s_{m}, \alpha_{m}\right)$ is a 2-tuple linguistic variable which is represented as the arithmetic mean.

In general, decision makers would use the different 2tuple linguistic variables based on their knowledge or experiences to express their opinions ${ }^{48}$. For example, the different linguistic variables show as Table 2 and Figs. 24. Each 2-tuple linguistic variable can be represented as a triangle fuzzy number. A transformation function is needed to transfer these 2-tuple linguistic variables from different linguistic sets to a standard linguistic set at unique domain. In the method of Herrera and Martinez ${ }^{45}$, the domain of the linguistic variables will increase as the number of linguistic variable is increased. To overcome this drawback, a new translation function is applied to transfer a crisp number or 2-tuple linguistic variable to a standard linguistic term at the unique domain ${ }^{46}$. Suppose that the interval $[0,1]$ is the unique domain. The linguistic variable sets with different semantics (or types) will be defined by partitioning the interval $[0,1]$. Transforming a crisp number $\beta(\beta \in[0,1])$ into a-th linguistic term $\left(s_{a}^{n(t)}, \alpha_{a}^{n(t)}\right)$ of type $\mathrm{t}$ as

$$
\Delta_{t}(\beta)=\left(s_{a}^{n(t)}, \alpha_{a}^{n(t)}\right)
$$

where $a=\operatorname{round}\left(\beta \times g_{t}\right), \alpha_{a}^{n(t)}=\beta-\frac{a}{g_{t}}, g_{t}=n(t)-1$.

$n(t)$ is the number of linguistic variable of type $t$.

Transforming $a$-th linguistic term of type t into a crisp number $\beta(\beta \in[0,1])$ as

$$
\Delta_{t}^{-1}\left(s_{a}^{n(t)}, \alpha_{a}^{n(t)}\right)=\frac{a}{g_{t}}+\alpha_{a}^{n(t)}=\beta
$$

where $g_{t}=n(t)-1$ and $\alpha_{a}^{n(t)} \in\left[-\frac{1}{2 g_{t}}, \frac{1}{2 g_{t}}\right)$.

Therefore, the transformation from $a$-th linguistic term $\left(s_{a}^{n(t)}, \alpha_{a}^{n(t)}\right)$ of type $\mathrm{t}$ to $\mathrm{k}$-th linguistic term $\left(s_{k}^{n(t+1)}, \alpha_{k}^{n(t+1)}\right)$ of type $\mathrm{t}+1$ at interval $[0,1]$ can be expressed as

$$
\Delta_{t+1}\left(\Delta_{t}^{-1}\left(s_{a}^{n(t)}, \alpha_{a}^{n(t)}\right)\right)=\left(s_{k}^{n(t+1)}, \alpha_{k}^{n(t+1)}\right)
$$

\section{The Maximum Deviation Method}

If the performance values among all the logistics suppliers are little differences with respect to criterion, it shows that the criterion plays a less important role in the decisionmaking procedure. Contrariwise, if one criterion makes the performance values among all the logistics suppliers have obvious differences, such a criterion plays a more important role in choosing the best logistics supplier. According to the concept, the maximizing deviation method $^{49}$ is applied to calculate the weight of each criterion.

Assume that an expert group has $\mathrm{K}$ experts, and the fuzzy rating of logistics supplier $A_{i}$ respect to criterion $C_{j}$ of each expert $E_{k}(k=1,2, \ldots, K)$ can be represented as a 2-tuple linguistic variable $\tilde{x}_{i j}^{k}=\left(S_{i j}^{k}, \alpha_{i j}^{k}\right)$. The deviation method is used to compute the differences of the performance values of each logistics suppliers with respect to all criteria. For the expert $E_{k}$ and the criterion $C_{j}$, the deviation of logistics suppliers $A_{i}$ to all the other logistics suppliers can be defined as

$$
H_{i j}^{k}(w)=\sum_{l=1}^{n}\left(\Delta^{-1}\left(\widetilde{x}_{i j}^{k}\right)-\Delta^{-1}\left(\widetilde{x}_{l j}^{k}\right)\right)^{2} w_{j}
$$

and 


$$
H_{j}^{k}(w)=\sum_{i=1 l=1}^{n} \sum^{n}\left(\Delta^{-1}\left(\widetilde{x}_{i j}^{k}\right)-\Delta^{-1}\left(\widetilde{x}_{l j}^{k}\right)\right)^{2} w_{j}
$$

The $H_{i j}^{k}(w)$ represents the deviation value of i-th supplier to other logistics suppliers with respect to the criterion $C_{j}$ by the expert $E_{k}$. The $H_{j}^{k}(w)$ represents the deviation value of all logistics suppliers to other logistics suppliers with respect to the criterion $C_{j}$ by the expert $E_{k}$. The $w_{j}$ represents the weight value of $j$-th criterion. Based on the maximum deviation method, a non-linear programming model can be constructed as ${ }^{50}$

$$
\begin{aligned}
& \max H(w)=\sum_{k=1}^{K} \lambda_{k} \sum_{j=1}^{m} \sum_{i=1 l=1}^{n} \sum_{i=1}^{n}\left(\Delta^{-1}\left(\tilde{x}_{i j}^{k}\right)-\Delta^{-1}\left(\widetilde{x}_{l j}^{k}\right)\right)^{2} w_{j} \\
& \text { s.t. } w_{j} \geq 0, \quad \sum_{j=1}^{m} w_{j}^{2}=1
\end{aligned}
$$

where $\lambda_{k}$ represents the weight of expert $E_{k}$. According to the computation process of maximizing deviation method $^{49}$, the weight of criterion $C_{j}$ can be calculated as $^{49}$

$$
w_{j}^{*}=\frac{\sum_{k=1}^{K} \lambda_{k} \sum_{i=1 l=1}^{n} \sum_{l=1}^{n}\left(\Delta^{-1}\left(\widetilde{x}_{i j}^{k}\right)-\Delta^{-1}\left(\widetilde{x}_{l j}^{k}\right)\right)^{2}}{\sum_{j=1}^{m} \sum_{k=1}^{K} \lambda_{k} \sum_{i=1 l=1}^{n} \sum_{l=1}^{n}\left(\Delta^{-1}\left(\widetilde{x}_{i j}^{k}\right)-\Delta^{-1}\left(\widetilde{x}_{l j}^{k}\right)\right)^{2}}
$$

\section{Proposed Method}

In fact, selection problem of logistics suppliers can be described by means of the following sets:

(i) A set of experts is called $\mathrm{E}=\left\{E_{1}, \mathrm{E}_{2}, \cdots, \mathrm{E}_{K}\right\}$;

(ii) $\mathrm{A}$ set of logistics suppliers (alternatives) is called $\mathrm{A}=\left\{\mathrm{A}_{1}, \mathrm{~A}_{2}, \cdots, \mathrm{A}_{m}\right\}$;

(iii) A set of criteria $\mathrm{C}=\left\{\mathrm{C}_{1}, \mathrm{C}_{2}, \cdots, \mathrm{C}_{n}\right\}$ with which performances are measured of logistics suppliers;

(iv) A set of performance ratings of logistics suppliers with respect to criteria is called $x_{i j}, i=1,2, \ldots, m$ $j=1,2, \ldots, n$.

If the performance of the i-th logistics supplier with respect to the $\mathrm{j}$-th criterion is quantitative information, it can be expressed as crisp value $\left(C V_{i j}\right)$. If the performance of the $i$-th logistics supplier with respect to the $\mathrm{j}$-th criterion is qualitative information, the performance of the i-th logistics supplier with respect to the $\mathrm{j}$-th criterion decided by the k-th expert can be represented as a 2-tuple linguistic variable $F_{j}^{k}\left(A_{i}\right)=\left(s_{i j}^{k}, \alpha_{i j}^{k}\right)$. Experts would use the different 2tuple linguistic variables based on their knowledge or experiences to express their opinions. It is needed to transfer these 2-tuple linguistic variables from different linguistic sets to a standard linguistic set at unique domain before aggregated these linguistic variables of experts' opinions.

If the experts' opinions have been transferred to a standard linguistic set at unique domain, the aggregated linguistic ratings $F_{j}\left(A_{i}\right)$ of the i-th logistics supplier with respect to the $j$-th criterion can be calculated as

$$
F_{j}\left(A_{i}\right)=\Delta\left(\frac{1}{K} \sum_{k=1}^{K} \Delta^{-1}\left(s_{i j}^{k}, \alpha_{i j}^{k}\right)\right)=\left(s_{i j}, \alpha_{i j}\right)
$$

We can transfer crisp value which belong to benefit criterion into linguistic ratings $F_{j}\left(A_{i}\right)$ as

$$
\Delta\left(\frac{C V_{i j}-\min _{i} C V_{i j}}{\max _{i} C V_{i j}-\min _{i} C V_{i j}}\right)=\Delta(\beta)=\left(s_{i j}, \alpha_{i j}\right)=F_{j}\left(A_{i}\right)
$$

Likewise, we can transfer crisp value which belong to cost criterion into linguistic ratings $F_{j}\left(A_{i}\right)$ as

$$
\Delta\left(1-\frac{C V_{i j}-\min _{i} C V_{i j}}{\max _{i} C V_{i j}-\min _{i} C V_{i j}}\right)=\Delta(\beta)=\left(s_{i j}, \alpha_{i j}\right)=F_{j}\left(A_{i}\right) \text { Fo }
$$

r comparing two logistics suppliers $A_{r}, A_{s} \in A$, under criterion $j$, the difference can be calculated as $d=\Delta^{-1}\left(F_{j}\left(A_{r}\right)\right)-\Delta^{-1}\left(F_{j}\left(A_{s}\right)\right)$. Therefore, a preference function $P$ is defined as:

$$
\begin{aligned}
& \quad P_{j}\left(A_{r}, A_{s}\right)=H_{j}\left(d_{j}^{r s}\right)=H_{j}\left(F_{j}\left(A_{r}\right), F_{j}\left(A_{s}\right)\right) \\
& 0 \leq P_{j}\left(A_{r}, A_{s}\right) \leq 1
\end{aligned}
$$

The symbol $P_{j}\left(A_{r}, A_{s}\right)$ represents the preference degree of logistics supplier $A_{r}$ over $A_{s}$ with respect to criterion $\mathrm{j}$. The $\mathrm{H}_{\mathrm{j}}\left(d_{j}^{r s}\right)$ is a monotonically increasing function of the observed deviation between $F_{j}\left(A_{r}\right)$ and $F_{j}\left(A_{s}\right)$ with respect to criterion $\mathrm{j}$.

There are six types of preference function in PROMETHEE method ${ }^{32-34}$ such as usual criterion, quasi criterion, criterion with linear preference, level criterion 
with linear preference, criterion with linear preference and indifference area, and guassian criterion.

Usual criterion can be expressed as follows

$$
H\left(F_{j}\left(A_{r}\right), F_{j}\left(A_{s}\right)\right)=\left\{\begin{array}{l}
1, \Delta^{-1}\left(F_{j}\left(A_{r}\right)\right)-\Delta^{-1}\left(F_{j}\left(A_{s}\right)\right)>0 \\
0, \Delta^{-1}\left(F_{j}\left(A_{r}\right)\right)-\Delta^{-1}\left(F_{j}\left(A_{s}\right)\right) \leq 0
\end{array}\right.
$$

Quasi criterion can be expressed as follows

$H\left(F_{j}\left(A_{r}\right), F_{j}\left(A_{s}\right)\right)=\left\{\begin{array}{l}1, \Delta^{-1}\left(F_{j}\left(A_{r}\right)\right)-\Delta^{-1}\left(F_{j}\left(A_{S}\right)\right)>l \\ 0, \Delta^{-1}\left(F_{j}\left(A_{r}\right)\right)-\Delta^{-1}\left(F_{j}\left(A_{s}\right)\right) \leq l\end{array}\right.$

Criterion with linear preference can be expressed as follows

$H\left(F_{j}\left(A_{r}\right), F_{j}\left(A_{s}\right)\right)=$

$$
\left\{\begin{array}{c}
\frac{\Delta^{-1}\left(F_{j}\left(A_{r}\right)\right)-\Delta^{-1}\left(F_{j}\left(A_{s}\right)\right)}{p}, p \geq \Delta^{-1}\left(F_{j}\left(A_{r}\right)\right)-\Delta^{-1}\left(F_{j}\left(A_{s}\right)\right) \geq 0 \\
0,0>\Delta^{-1}\left(F_{j}\left(A_{r}\right)\right)-\Delta^{-1}\left(F_{j}\left(A_{s}\right)\right)
\end{array}\right.
$$

Level criterion with linear preference can be expressed as follows

$$
\begin{aligned}
& H\left(F_{j}\left(A_{r}\right), F_{j}\left(A_{s}\right)\right)= \\
& \left\{\begin{array}{l}
1, \Delta^{-1}\left(F_{j}\left(A_{r}\right)\right)-\Delta^{-1}\left(F_{j}\left(A_{s}\right)\right)>p \\
\frac{1}{2}, p \geq \Delta^{-1}\left(F_{j}\left(A_{r}\right)\right)-\Delta^{-1}\left(F_{j}\left(A_{s}\right)\right) \geq q \\
0, q>\Delta^{-1}\left(F_{j}\left(A_{r}\right)\right)-\Delta^{-1}\left(F_{j}\left(A_{s}\right)\right)
\end{array}\right.
\end{aligned}
$$

Criterion with linear preference and indifference area can be expressed as follows $H\left(F_{j}\left(A_{r}\right), F_{j}\left(A_{s}\right)\right)=$

$$
\left\{\begin{array}{c}
1, \Delta^{-1}\left(F_{j}\left(A_{r}\right)\right)-\Delta^{-1}\left(F_{j}\left(A_{s}\right)\right)>p \\
\frac{\Delta^{-1}\left(F_{j}\left(A_{r}\right)\right)-\Delta^{-1}\left(F_{j}\left(A_{s}\right)\right)-q}{p-q}, p \geq \Delta^{-1}\left(F_{j}\left(A_{r}\right)\right)-\Delta^{-1}\left(F_{j}\left(A_{s}\right)\right) \geq q \\
0, q>\Delta^{-1}\left(F_{j}\left(A_{r}\right)\right)-\Delta^{-1}\left(F_{j}\left(A_{s}\right)\right)
\end{array}\right.
$$

Guassian criterion can be expressed as follows

$$
\begin{aligned}
& H\left(F_{j}\left(A_{r}\right), F_{j}\left(A_{s}\right)\right)= \\
& \left\{\begin{array}{c}
\frac{-\left(\Delta^{-1}\left(F_{j}\left(A_{r}\right)\right)-\Delta^{-1}\left(F_{j}\left(A_{s}\right)\right)\right)^{2}}{2 \sigma^{2}} \\
1-e \quad, \Delta^{-1}\left(F_{j}\left(A_{r}\right)\right)-\Delta^{-1}\left(F_{j}\left(A_{s}\right)\right)>0 \\
0, \Delta^{-1}\left(F_{j}\left(A_{r}\right)\right)-\Delta^{-1}\left(F_{j}\left(A_{s}\right)\right) \leq 0
\end{array}\right.
\end{aligned}
$$

The overall preference index of logistics supplier $A_{r}$ over logistics supplier $A_{S}$ can be represented as

$$
\pi\left(A_{r}, A_{s}\right)=\sum_{j=1}^{n} w_{j}^{*} * H_{j}\left(d_{j}^{r s}\right)
$$

where $w_{j}^{*}$ is the weight of criterion $C_{j}$ is determined by maximum deviation method.

The leaving flow of $A_{r}$ can be calculated as

$$
\phi^{+}\left(A_{r}\right)=\sum_{\substack{b \in A \\ b \neq A_{r}}} \pi\left(A_{r}, b\right)
$$

$\phi^{+}\left(A_{r}\right)$ is the measure of the dominating degree of $A_{r}$ over the other logistics suppliers .

The entering flow of $A_{r}$ can be calculated as

$$
\phi^{-}\left(A_{r}\right)=\sum_{\substack{b \in A \\ b \neq A_{r}}} \pi\left(b, A_{r}\right)
$$

$\phi^{-}\left(A_{r}\right)$ is the measure of the dominated degree of $A_{r}$ by the other logistics suppliers.

The net flow of $A_{r}$ can be calculated as

$$
\phi\left(A_{r}\right)=\phi^{+}\left(A_{r}\right)-\phi^{-}\left(A_{r}\right)
$$

Define the outranking index of logistics supplier $A_{r}$ as:

$$
\operatorname{OTI}\left(A_{r}\right)=\frac{\frac{\phi\left(A_{r}\right)}{n-1}+1}{2}
$$

where $\mathrm{n}$ is the number of logistics supplier. The range of OTI is between 0 and 1 , the higher the value of OTI, the better the logistics supplier. However, a more realistic approach may be to use a linguistic variable to describe the current assessment status of each logistics supplier in accordance with its outranking index. Therefore, transform the outranking index of each logistics supplier into 2-tuple linguistic variable as $\Delta\left(\operatorname{OTI}\left(A_{r}\right)\right)=\left(s_{r}, \alpha_{r}\right)$. According to the 2-tuple linguistic outranking index of each logistics supplier, one can determine the ranking order and the current assessment status of each logistics supplier by using a 2-tuple linguistic variable.

\section{A Numerical Example}

Suppose that a furniture factory desires to select a logistics supplier to deliver their product to his customer. In the enterprise, enterprise manager wants to choose the 
best logistics suppliers from four candidates in accordance with six criteria. These criteria are price, ontime deliveries, service quality, financial structure, relationship closeness, and information technology.

The price, financial structure and on-time deliveries are quantitative information. Price can be represented by the advantage expense which furniture factory must pay when supplier delivered furniture to one customer. Ontime delivery represents the ratio of logistics supplier deliver product to customers in the customers' appointed time. We can collect from the customers' response opinion and arrange the ratio of delivery delay. Service quality which is the degree of customers' satisfactory, we can collect from the customers by questionnaires. Financial structure means the risk of a company will go out of business. Relationship closeness means the relationship between enterprise and logistics supplier. Information technology means the information system which logistics supplier provides to customer. Financial structure, relationship closeness and information technology can be expressed by experts' opinions according to suitable level of linguistic variables. The description about the criteria is shown in Table 3.

According to the proposed method, the computational procedures of the problem are summarized as follows.

Step 1. Collect the quantity information as Table 4.

Step 2. Transform the quantity information into 2-tuple linguistic variable of level 2 as Table 5.

Step 3. The information about service quality respect to each logistics supplier is collected from three customers' opinions as Table 6. Each customer chooses suitable level of linguistic variables according to his/her preference to express his/her opinion about the service quality of each supplier.

Step 4. Transform customers' opinions about service quality of each logistics supplier into 2-tuple linguistic variable of type 2 and then aggregate the linguistic ratings of each logistics supplier as Table 7.

Step 5. Each expert chooses the suitable level of linguistic variables. Expert $D_{1}$ chooses level 1, $D_{2}$ chooses level $2, D_{3}$ and chooses level 3 (refer to Table 2). And then, each expert uses the linguistic variables evaluate the performance ratings of each logistics supplier with respect to financial structure criterion, relationship closeness criterion and information technology criterion as Table 8 .
Step 6. Transform experts' opinions into 2-tuple linguistic variable of level 2 and then aggregate the linguistic ratings of each logistics supplier with respect to criteria as Table 9.

Step 7. Determine the threshold values of each criterion as Table 10 .

Step 8. Calculate the preference degree $\mathrm{H}(\mathrm{d})$ of all logistics suppliers with respect to each criterion as Tables 11-16 and the preference function of each criterion please refers to Table 3 .

Step 9. In this paper, the importance of each expert is equally. Thus, $\lambda_{1}=\lambda_{2}=\lambda_{3}=\frac{1}{3}$. We computed the weight of each criterion by maximize deviation method (equation 12) in accordance with each expert's opinion which is about the performance of each logistics supplier with respect to each criterion as.

$$
\begin{aligned}
& w_{1}^{*}=0.299, w_{2}^{*}=0.294, w_{3}^{*}=0.104, w_{4}^{*}=0.081, \\
& w_{5}^{*}=0.115, w_{6}^{*}=0.108 .
\end{aligned}
$$

Step 10. Calculate the overall preference index of each logistics supplier as Table 17.

Step 11. Calculate the leaving flow, the entering flow, the net flow, the outranking index and linguistic variable at level 1 of each logistics supplier as Table 18. Finally, the ranking order of all logistics suppliers according to the outranking index is $\left\{A_{1}>A_{3}>A_{2}\right\}>A_{4}$.

According to the linguistic variable, logistics suppliers $A_{1}, A_{2}$ and $A_{3}$ are in the same level and can be expressed as "fair" suppliers. But, $A_{1}$ is slightly superior than $A_{2}$ and $A_{3}$. Logistics supplier $A_{4}$ can be expressed as a "poor" supplier.

\section{Conclusions}

In this paper, we developed a framework for selecting logistics suppliers which both considers quantitative and qualitative criteria. The information about judging the performance of logistics supplier comes from customers' opinions, experts' opinions and the realistic data such as advantage expense per logistics service activity, ratio of correct delivery on time. So, we considered many dimensions which are suitable for selecting the logistics supplier in realistic environment. Considering the conflicting criteria such as service quality and outsource 
cost exists in choosing the best logistics supplier and avoiding the subjective judgment of experts, we presented a MCDM method by combining linguistic PROMETHEE with maximum deviation method for determining the ranking order and the level of logistics suppliers. In the future, we will develop a decision support system based on the framework and enhance the practical value of the proposed method.

\section{References}

1. J. Cao, G. Cao and W. W. Wang, A Hybrid MCDM Integrated Borda Function and Gray Rational Analysis for 3PLs Selection, 2007 IEEE International Conference on Grey Systems and Intelligent Services, (2007), pp. 18-20.

2. E. Sucky, A model for dynamic strategic vendor selection, Computers \& Operations Research, 34(12)(2007), pp. 36383651.

3. G. Isıklar, E. Alptekin and G. Buyukozkan, Application of a hybrid intelligent decision support model in logistics outsourcing, Computers \& Operations Research, 34(12)(2007), pp. 3701-3714.

4. G. Kannan, S. Pokharel and P. S. Kumar, A hybrid approach using ISM and fuzzy TOPSIS for the selection of reverse logistics provider, Resources, Conservation and Recycling, 54(1)(2009), pp. 28-36.

5. H. J. Ko and G. W. Evans, A genetic algorithm-based heuristic for the dynamic integrated forward/ reverse logistics network for 3PLs, Computers \& Operations Research, (2007), pp. 346-366.

6. C. Araz, P. M. Ozfirat and I. Ozkarahan, An integrated multicriteria decision -making methodology for outsourcing management, Computers \& Operations Research, 34(12)(2007), pp. 3738-3756.

7. R. Handfisld, S. V. Walton R. Stroufe and S. A. Melnyk, Applying environmental criteria to supplier assessment: A study in the application of the analytical hierarchy process, European Journal of Operational Research, 141(1)(2002), pp. $70-87$.

8. F. T. S. Chan and N. Kumar, Global supplier development considering risk factors using fuzzy extended AHP-based approach, OMEGA, 35(2007), pp. 417-431,.

9. O. Bayazit, Use of analytic network process in vendor selection decisions, Benchmarking: An International Journal , 13(5)(2006), pp. 566-579.

10. C. Gencer and D. Gurpinar, Analytic network process in supplier selection: A case study in an electronic firm, Applied Mathematical Modeling, 31(11)(2007), pp. 24752486.

11. C. T. Chen, C. T. Lin and S. F. Huang, A fuzzy approach for supplier evaluation and selection in supply chain management, International Journal of Production Economics, 102(2)(2006), pp. 289-301.

12. C. K. Kwong, W. H. Ip and J. W. K. Chan, Combining scoring method and fuzzy expert systems approach to supplier assessment: A case study, Integrated Manufacturing Systems, 13(7)(2002), pp. 512-519.

13. T. Wu, D. Shunk J. Blackhurst and R. Appalla, AIDEA: A methodology for supplier evaluation and selection in a supplier-based manufacturing environment, International Journal of Manufacturing Technology and Management, 11(2)(2007), pp. 174-192.

14. R. M. Garfamy, A data envelopment analysis approach based on total cost of ownership for supplier selection, Journal of Enterprise Information Management, 19(6)(2006), pp. 662-678.

15. S. Talluri and R. Narasimhan, Vendor evaluation with performance variability: A max-min approach, European Journal of Operational Research, 146(3)(2003), pp. 543-552.

16. W. L. Ng, An efficient and simple model for multiple criteria supplier selection problem, European Journal of Operational Research, 186(3)(2008), pp. 1059-1067.

17. G. H. Hong, S. C. Park D. S. Jang and H. M. Rho, An effective supplier selection method for constructing a competitive supply-relationship, Expert Systems with Applications, 28(4)(2005), pp. 629-639.

18. S. Talluri, A buyer-seller game model for selection and negotiation of purchasing bids, European Journal of Operational Research, 143(1)(2002), pp. 171-180.

19. R. Narasimhan, S. Talluri and S. K. Mahapatra, Multiproduct, multicriteria model for supplier selection with product life-cycle considerations, Decision Sciences, 37(4)(2006), pp. 577-603.

20. V. Wadhwa and A. R. Ravindran, "Vendor selection in outsourcing. Computers and Operations Research", 34(12)(2007), pp. 3725-3737.

21. H. Ding, L. Benyoucef and X. Xie, A simulation optimization methodology for supplier selection problem, International Journal Computer Integrated Manufacturing, 18(2-3)(2005), pp. 210-224.

22. G. Isıklar, E. Alptekin and G. Buyukozkan, Application of a hybrid intelligent decision support model in logistics outsourcing, Computers \& Operations Research, 34(12)(2007), pp. 3701-3714.

23. A. S. Carr and J. N. Pearson, The impact of purchasing and supplier involvement on strategic purchasing and its impact on firm's performance, International Journal of Operations and Production Management, 22(9)(2002), pp. 1032-1055.

24. F. E. Boran, S. Genç M. Kurt and D. Akay, A multi-criteria intuitionistic fuzzy group decision making for supplier selection with TOPSIS method, Expert Systems with Applications, 36(8)(2009), pp. 11363-11368.

25. S. Jharkharia and R. Shankar, Selection of logistics service provider: An analytic network process (ANP) approach, 
Omega, 35(2007), pp. $274-289$.

26. J. W. Wang, C. H. Cheng and H. K. Cheng, Fuzzy hierarchical TOPSIS for supplier selection, Applied Soft Computing, 9 (2009), pp. 377-386.

27. Z. H. Yin, N. Wang and Q. Lu, Third-party Logistics Suppliers Selection based on Grey Situation Decision and Information Entropy, International Workshop on Intelligent Systems and Applications, (2009), pp.1-3.

28. X. L. Tang, Study On Selection Of Logistics Supplier Based On Support Vector Machine, the Eighth International Conference on Machine Learning and Cybernetics, Baoding (2009), pp. 12-15.

29. F. Herrera and L. Martinez, A 2-tuple fuzzy linguistic representation model for computing with words, IEEE Transactions on Fuzzy Systems, 8(6)(2000), pp. 746-752.

30. Z. S. Xu, Deviation measures of linguistic preference relations in group decision making, Omega, 33(2005), pp. 249-254.

31. E. Herrera-Viedma, O. Cordón and M. Luque, A. G. Lopez and A. M. Muñoz, A model of fuzzy linguistic IRS based on multigranular linguistic information, International Journal of Approximate Reasoning, 34(2-3)(2003), pp. 221-239.

32. J. P. Brans, B. Mareschal and Ph. Vincke, PROMETHEE: A new family of outranking methods in MCDM, Operational Research, (1984), pp.477-490.

33. M. Goumas and V. Lygerou, An extension of the PROMETHEE method for decision making in fuzzy environment: ranking of alternative energy exploitation projects, European Journal of Operational Research, 123(2000), pp. 606-613.

34. J. P. Brans and $\mathrm{Ph}$. Vincke, A preference ranking organization method (the PROMETHEE method for MCDM), Management Science, 31(1985), pp. 647-656.

35. Y. M. Wang, Using the method of maximizing deviations to make decision for multi-indices, System Engineering and Electronics, 7(1998), pp. 24-26.

36. C. T. Chen and W. Z. Hung, Applying ELECTRE and maximizing deviation method for stock portfolio selection under fuzzy environment, The Twenty Second International Conference on Industrial, Engineering and Other Applications of Applied Intelligent Systems, 2009.

37. L. A. Zadeh, Fuzzy sets, Information and Control, 8(3)(1965), pp. 338-353.

38. R. R. Yager, An approach to ordinal decision making, International Journal of Approximate Reasoning, 12(1995), pp. 233-261.
39. C. T. Lin and Y. T. Chen, Bid/no-bid decision-making - a fuzzy linguistic approach, International, Journal of Project Management, 22(2004), pp. 585-593.

40. R. C. Wang and S. J. Chuu, Group decision-making using a fuzzy linguistic approach for evaluating the flexibility in a manufacturing system, European Journal of Operational Research, 154(2004), pp. 563-572.

41. C. T. Chen, Extensions of the TOPSIS for group decisionmaking under fuzzy environment, Fuzzy Sets and Systems, 114(2000), pp. 1-9.

42. E. Herrera-Viedma and E. Peis, Evaluating the informative quality of documents in SGML format from judgments by means of fuzzy linguistic techniques based on computing with words, Information Processing and Management, 39(2003), pp. 233-249.

43. L. A. Zadeh, The concept of a linguistic variable and its application to approximate reasoning, Information Sciences, 8(1975), pp.199-249(I), pp.301-357(II).

44. A. Kaufmann and M. M. Gupta, Introduction to Fuzzy Arithmetic: Theory and Applications, International Thomson Computer Press, 1991.

45. F. Herrera and L. Martinez, A model based on linguistic 2tuples for dealing with multigranular hierarchical linguistic contexts in multi-expert decision-making, IEEE Transactions on Systems, Man, and Cybernetics Part B: Cybernetics, 31(2001), pp. 227-234.

46. W. S. Tai and C. T. Chen, A new evaluation model for intellectual capital based on computing with linguistic variable, Expert Systems with Applications, 36(2009), pp. 3483-3488.

47. E. Herrera-Viedma, F. Herrera L. Martínez J. C. Herrera and A. G. López, Incorporating filtering techniques in a fuzzy linguistic multi-agent model for information gathering on the web, Fuzzy Sets and Systems, 148(2004), pp. 61-83.

48. F. Herrera, L. Martinez and P. J. Sanchez, Managing nonhomogeneous information in group decision making, European Journal of Operational Research, 166(2005), pp. $115-132$

49. Z. Wu and Y. Chen, The maximizing deviation method for group multiple attribute decision making under linguistic environment. Fuzzy Sets and Systems, 158(2007), pp. 1608 1617. 
Table 1. The collected criteria from the literatures

\begin{tabular}{|c|c|c|c|c|c|c|c|c|c|}
\hline & $\begin{array}{l}\text { Cao } \\
\text { et al. }{ }^{1}\end{array}$ & $\begin{array}{c}\text { Kannan } \\
\text { et al. }{ }^{4}\end{array}$ & $\begin{array}{l}\text { Chan } \\
\text { et al. }\end{array}$ & $\begin{array}{l}\text { Chen } \\
\text { et al. }\end{array}$ & $\begin{array}{l}\text { Boran } \\
\text { et al. }\end{array}$ & $\begin{array}{c}\text { Jharkharia } \\
\text { et al. }^{25}\end{array}$ & $\begin{array}{l}\text { Wang } \\
\text { et al. }\end{array}$ & $\begin{array}{l}\text { Yin } \\
\text { et al. }^{27}\end{array}$ & Tang $^{28}$ \\
\hline Price & $\bullet$ & 0 & $\bullet$ & & $\bullet$ & $\bullet$ & $\bullet$ & $\bullet$ & - \\
\hline Financial Structure & & & $\bullet$ & $\bullet$ & & $\bullet$ & & & \\
\hline Market Share & & & - & & & & & - & \\
\hline On-time Deliveries & - & - & - & & - & & - & - & - \\
\hline Service Quality & - & - & - & - & & - & & $\bullet$ & - \\
\hline $\begin{array}{l}\text { Value-Added } \\
\text { Services } \\
\text { KPI (Key } \\
\text { Performance } \\
\text { Indicator) } \\
\text { Measurement }\end{array}$ & 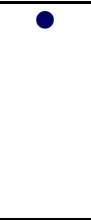 & & & & & 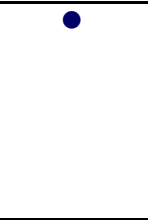 & & & \\
\hline Reputation & $\bullet$ & & & & & $\bullet$ & & & \\
\hline Reject Rate & & 0 & 0 & & & & & & \\
\hline $\begin{array}{l}\text { Technical } \\
\text { Capability }\end{array}$ & & $\bullet$ & & $\boldsymbol{\bullet}$ & & & & & \\
\hline $\begin{array}{l}\text { Inability to meet } \\
\text { future requirement }\end{array}$ & & $\bullet$ & & & & & & & \\
\hline $\begin{array}{l}\text { Willingness and } \\
\text { Attitude }\end{array}$ & & $\bullet$ & & & & & & & \\
\hline $\begin{array}{l}\text { Relationship } \\
\text { closeness }\end{array}$ & & & & $\bullet$ & $\bullet$ & $\bullet$ & & & \\
\hline Conflict Resolution & & & & - & & & & & \\
\hline Lead Time & & & 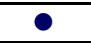 & & & & & & \\
\hline $\begin{array}{l}\text { Technological and } \\
\text { R\&D support }\end{array}$ & & & $\bullet$ & & & & & & \\
\hline $\begin{array}{l}\text { Response to } \\
\text { Changes }\end{array}$ & & & ○ & & & & $\bullet$ & & \\
\hline Communication & 0 & & 0 & & & & & & \\
\hline $\begin{array}{l}\text { Performance } \\
\text { History }\end{array}$ & & & $\boldsymbol{0}$ & & & & & & \\
\hline $\begin{array}{l}\text { Production Facility } \\
\text { and Capacity }\end{array}$ & & & $\bullet$ & & & & & & \\
\hline Political Stability & & & - & & & & & & \\
\hline Economy & & & - & & & & & & \\
\hline Terrorism & & & - & & & & & & \\
\hline Product Quality & & & & & - & & & & \\
\hline Compatibility & & & & & & $\bullet$ & & & \\
\hline Risk Management & & & & & & $\bullet$ & & & \\
\hline Flexibility & - & & & & & & - & & \\
\hline $\begin{array}{l}\text { Key Quality } \\
\text { Characteristics }\end{array}$ & & & & & & & $\bullet$ & & \\
\hline $\begin{array}{l}\text { Information } \\
\text { Technology }\end{array}$ & $\bullet$ & & & & & & & - & $\bullet$ \\
\hline Location & - & & & & & & & & \\
\hline Global capability & - & & & & & & & & \\
\hline Scope of enterprise & & & & & & & & - & - \\
\hline $\begin{array}{l}\text { Innovation } \\
\text { capability }\end{array}$ & & & & & & & & $\bullet$ & \\
\hline $\begin{array}{l}\text { Credibility and } \\
\text { culture }\end{array}$ & & & & & & & & $\bullet$ & $\bullet$ \\
\hline
\end{tabular}




\begin{tabular}{|l|l|l|l|l|l|l|l|l|l|}
\hline $\begin{array}{l}\text { Risk degree of } \\
\text { cooperation }\end{array}$ & & & & & & & & $\bullet$ & \\
\hline $\begin{array}{l}\text { Impact on } \\
\text { environment }\end{array}$ & & & & & & & & $\bullet$ & \\
\hline $\begin{array}{l}\text { Transportation } \\
\text { capacity }\end{array}$ & & & & & & & & & $\bullet$ \\
\hline Storage capacity & & & & & & & & & $\bullet$ \\
\hline $\begin{array}{l}\text { Organization } \\
\text { learning ability }\end{array}$ & & & & & & & & $\bullet$ \\
\hline
\end{tabular}

Table 2. Different levels of linguistic variables

\begin{tabular}{|c|c|c|}
\hline Levels & Linguistic variables & Figure \\
\hline 1 & Extremely Poor $\left(s_{0}^{5}\right)$, Poor $\left(s_{1}^{5}\right)$, Fair $\left(s_{2}^{5}\right), \operatorname{Good}\left(s_{3}^{5}\right)$, Extremely Good $\left(s_{4}^{5}\right)$ & Fig 2. \\
\hline 2 & $\begin{array}{l}\text { Extremely Poor }\left(s_{0}^{7}\right), \operatorname{Poor}\left(s_{1}^{7}\right), \operatorname{Medium} \text { Poor }\left(s_{2}^{7}\right), \operatorname{Fair}\left(s_{3}^{7}\right), \operatorname{Medium} \operatorname{Good}\left(s_{4}^{7}\right), \operatorname{Good}\left(s_{5}^{7}\right), \\
\text { Extremely } \operatorname{Good}\left(s_{6}^{7}\right)\end{array}$ & Fig 3. \\
\hline 3 & $\begin{array}{l}\text { Extremely Poor }\left(s_{0}^{9}\right), \text { Very Poor }\left(s_{1}^{9}\right), \text { Poor }\left(s_{2}^{9}\right), \text { Medium Poor }\left(s_{3}^{9}\right), \text { Fair }\left(s_{4}^{9}\right) \text {, Medium } \\
\operatorname{Good}\left(s_{5}^{9}\right), \operatorname{Good}\left(s_{6}^{9}\right), \operatorname{Very} \operatorname{Good}\left(s_{7}^{9}\right), \text { Extremely } \operatorname{Good}\left(s_{8}^{9}\right)\end{array}$ & Fig 4. \\
\hline
\end{tabular}

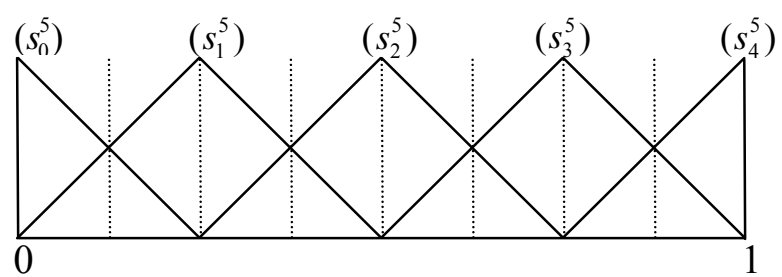

Fig. 2. Membership functions of linguistic variables at level $1(t=1)$

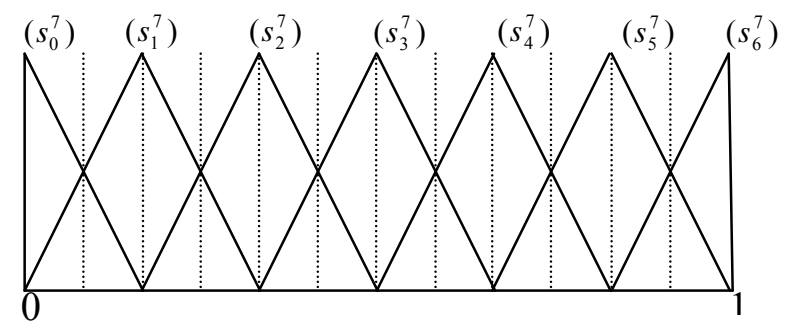

F1g. 3. Membership functions of linguistic variables at level $2(t=2)$

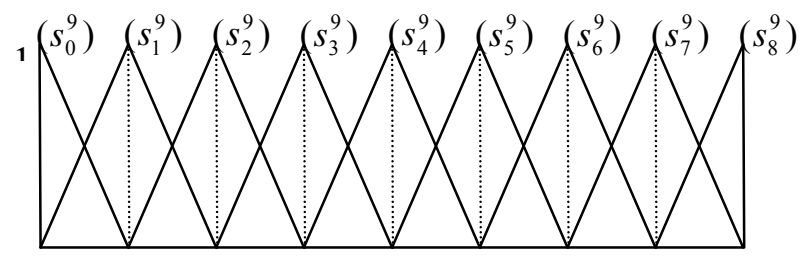

0

Fig. 4. Membership functions of linguistic variables at level $3(t=3)$ 
Table 3. The Description of the criteria

\begin{tabular}{|l|l|l|l|}
\hline Name & Data type & Information & Preference function \\
\hline$C_{1}$ (Price) & $\begin{array}{l}\text { Quantity } \\
\text { (Cost } \\
\text { Criterion) }\end{array}$ & Advantage expense per service & $\begin{array}{l}\text { Criterion with linear preference } \\
\text { and indifference area }\end{array}$ \\
\hline$C_{2}$ (On time Deliveries) & $\begin{array}{l}\text { Quantity } \\
\text { Cost } \\
\text { Criterion) }\end{array}$ & Ratio of delivery Delay & Criterion with linear preference \\
\hline$C_{3}$ (Service Quality) & Quality & $\begin{array}{l}\text { The degree of customers' satisfaction } \\
\text { Judged by customers }\end{array}$ & $\begin{array}{l}\text { Level criterion with linear } \\
\text { preference }\end{array}$ \\
\hline$C_{4}$ (Financial Structure) & Quality & $\begin{array}{l}\text { the risk of a company will go out of } \\
\text { business. } \\
\text { Judged by experts }\end{array}$ & $\begin{array}{l}\text { Criterion with linear preference } \\
\text { and indifference area }\end{array}$ \\
\hline$C_{5}$ (Relationship Closeness) & Quality & $\begin{array}{l}\text { Relationship between enterprise and } \\
\text { logistics supplier. } \\
\text { Judged by experts }\end{array}$ & $\begin{array}{l}\text { Level criterion with linear } \\
\text { preference }\end{array}$ \\
\hline$C_{6}$ (Information Technology) & Quality & $\begin{array}{l}\text { the information system which logistics } \\
\text { supplier provides to customer } \\
\text { Judged by experts }\end{array}$ & Criterion with linear preference \\
\hline
\end{tabular}

Table 4. Quantitative information

\begin{tabular}{|l|c|c|c|c|}
\hline & $A_{1}$ & $A_{2}$ & $A_{3}$ & $A_{4}$ \\
\hline $\begin{array}{l}C_{1} \text { Price (U.S. } \\
\text { Dollar) }\end{array}$ & 3 & 2.5 & 4 & 3.5 \\
\hline $\begin{array}{l}C_{2} \\
\begin{array}{l}\text { On time Deliveries } \\
\text { (Ratio of Delivery } \\
\text { Delay) }\end{array}\end{array}$ & $1.5 \%$ & $3 \%$ & $1 \%$ & $2 \%$ \\
\hline
\end{tabular}

Table 5. Linguistic variable of quantitative information

\begin{tabular}{|l|c|c|c|c|}
\hline & $A_{1}$ & $A_{2}$ & $A_{3}$ & $A_{4}$ \\
\hline $\begin{array}{l}C_{1} \text { Price (U.S. } \\
\text { Dollar) }\end{array}$ & $\left(s_{4}^{7}, 0\right)$ & $\left(s_{6}^{7}, 0\right)$ & $\left(s_{0}^{7}, 0\right)$ & $\left(s_{2}^{7}, 0\right)$ \\
\hline $\begin{array}{l}C_{2} \\
\begin{array}{l}\text { On time Deliveries } \\
\text { (Ratio of Delivery } \\
\text { Delay) }\end{array}\end{array}$ & $\left(s_{5}^{7},-0.083\right)$ & $\left(s_{0}^{7}, 0\right)$ & $\left(s_{6}^{7}, 0\right)$ & $\left(s_{3}^{7}, 0\right)$ \\
\hline
\end{tabular}

Table 6. Customers' opinions about service quality

\begin{tabular}{|c|c|c|c|}
\hline & $C u_{1}$ & $\mathrm{Cu}_{2}$ & $\mathrm{Cu}_{3}$ \\
\hline$A_{1}$ & $\left(s_{2}^{5}, 0\right)$ & $\left(s_{6}^{7}, 0\right)$ & $\left(s_{6}^{9}, 0\right)$ \\
\hline$A_{2}$ & $\left(s_{4}^{5}, 0\right)$ & $\left(s_{5}^{7}, 0\right)$ & $\left(s_{8}^{9}, 0\right)$ \\
\hline$A_{3}$ & $\left(s_{3}^{5}, 0\right)$ & $\left(s_{5}^{7}, 0\right)$ & $\left(s_{8}^{9}, 0\right)$ \\
\hline$A_{4}$ & $\left(s_{2}^{5}, 0\right)$ & $\left(s_{2}^{7}, 0\right)$ & $\left(s_{4}^{9}, 0\right)$ \\
\hline
\end{tabular}

Table 7. Customers' opinions represented and aggregated by the linguistic variable of level 2

\begin{tabular}{|c|c|c|c|c|}
\hline & $C u_{1}$ & $C u_{2}$ & $C u_{3}$ & average \\
\hline$A_{1}$ & $\left(s_{3}^{7}, 0\right)$ & $\left(s_{6}^{7}, 0\right)$ & $\left(s_{5}^{7},-0.083\right)$ & $\left(s_{5}^{7},-0.083\right)$ \\
\hline$A_{2}$ & $\left(s_{6}^{7}, 0\right)$ & $\left(s_{5}^{7}, 0\right)$ & $\left(s_{6}^{7}, 0\right)$ & $\left(s_{6}^{7},-0.056\right)$ \\
\hline$A_{3}$ & $\left(s_{5}^{7},-0.083\right)$ & $\left(s_{5}^{7}, 0\right)$ & $\left(s_{6}^{7}, 0\right)$ & $\left(s_{5}^{7}, 0.028\right)$ \\
\hline$A_{4}$ & $\left(s_{3}^{7}, 0\right)$ & $\left(s_{2}^{7}, 0\right)$ & $\left(s_{3}^{7}, 0\right)$ & $\left(s_{3}^{7},-0.056\right)$ \\
\hline
\end{tabular}

Table 8 . The rating linguistic variable by experts

\begin{tabular}{|c|c|c|c|c|}
\hline Criterion & $\begin{array}{c}\text { Logistics } \\
\text { supplier }\end{array}$ & $\mathrm{D}_{1}$ & $\mathrm{D}_{2}$ & $\mathrm{D}_{3}$ \\
\hline \multirow{4}{*}{$C_{4}$} & $A_{1}$ & $\left(s_{4}^{5}, 0\right)$ & $\left(s_{5}^{7}, 0\right)$ & $\left(s_{4}^{9}, 0\right)$ \\
\cline { 2 - 5 } & $A_{2}$ & $\left(s_{3}^{5}, 0\right)$ & $\left(s_{2}^{7}, 0\right)$ & $\left(s_{8}^{9}, 0\right)$ \\
\cline { 2 - 5 } & $A_{3}$ & $\left(s_{3}^{5}, 0\right)$ & $\left(s_{3}^{7}, 0\right)$ & $\left(s_{6}^{9}, 0\right)$ \\
\cline { 2 - 5 } & $A_{4}$ & $\left(s_{2}^{5}, 0\right)$ & $\left(s_{5}^{7}, 0\right)$ & $\left(s_{5}^{9}, 0\right)$ \\
\hline \multirow{5}{*}{$C_{5}$} & $A_{1}$ & $\left(s_{4}^{5}, 0\right)$ & $\left(s_{6}^{7}, 0\right)$ & $\left(s_{8}^{9}, 0\right)$ \\
\cline { 2 - 5 } & $A_{2}$ & $\left(s_{3}^{5}, 0\right)$ & $\left(s_{2}^{7}, 0\right)$ & $\left(s_{8}^{9}, 0\right)$ \\
\cline { 2 - 5 } & $A_{3}$ & $\left(s_{4}^{5}, 0\right)$ & $\left(s_{5}^{7}, 0\right)$ & $\left(s_{6}^{9}, 0\right)$ \\
\cline { 2 - 5 } & $A_{4}$ & $\left(s_{4}^{5}, 0\right)$ & $\left(s_{6}^{7}, 0\right)$ & $\left(s_{8}^{9}, 0\right)$ \\
\hline \multirow{5}{*}{$C_{6}$} & $A_{1}$ & $\left(s_{3}^{5}, 0\right)$ & $\left(s_{2}^{7}, 0\right)$ & $\left(s_{2}^{9}, 0\right)$ \\
\cline { 2 - 5 } & $A_{2}$ & $\left(s_{2}^{5}, 0\right)$ & $\left(s_{5}^{7}, 0\right)$ & $\left(s_{4}^{9}, 0\right)$ \\
\cline { 2 - 5 } & $A_{3}$ & $\left(s_{4}^{5}, 0\right)$ & $\left(s_{5}^{7}, 0\right)$ & $\left(s_{8}^{9}, 0\right)$ \\
\cline { 2 - 5 } & $A_{4}$ & $\left(s_{2}^{5}, 0\right)$ & $\left(s_{4}^{7}, 0\right)$ & $\left(s_{4}^{9}, 0\right)$ \\
\hline
\end{tabular}


Table 9. Experts opinions represented and aggregated by the linguistic variable of level 2

\begin{tabular}{|c|c|c|c|c|c|}
\hline Criterion & $\begin{array}{c}\text { Logistics } \\
\text { supplier }\end{array}$ & $\mathrm{D}_{1}$ & $\mathrm{D}_{2}$ & $\mathrm{D}_{3}$ & average \\
\hline \multirow{5}{*}{$C_{4}$} & $A_{1}$ & $\left(s_{6}^{7}, 0\right)$ & $\left(s_{5}^{7}, 0\right)$ & $\left(s_{3}^{7}, 0\right)$ & $\left(s_{5}^{7},-0.056\right)$ \\
\cline { 2 - 6 } & $A_{2}$ & $\left(s_{5}^{7},-0.083\right)$ & $\left(s_{2}^{7}, 0\right)$ & $\left(s_{6}^{7}, 0\right)$ & $\left(s_{4}^{7}, 0.028\right)$ \\
\cline { 2 - 6 } & $A_{3}$ & $\left(s_{5}^{7},-0.083\right)$ & $\left(s_{3}^{7}, 0\right)$ & $\left(s_{5}^{7},-0.083\right)$ & $\left(s_{5}^{7},-0.083\right)$ \\
\cline { 2 - 6 } & $A_{4}$ & $\left(s_{3}^{7}, 0\right)$ & $\left(s_{5}^{7}, 0\right)$ & $\left(s_{4}^{7},-0.042\right)$ & $\left(s_{4}^{7},-0.014\right)$ \\
\hline \multirow{5}{*}{$C_{5}$} & $A_{1}$ & $\left(s_{6}^{7}, 0\right)$ & $\left(s_{6}^{7}, 0\right)$ & $\left(s_{6}^{7}, 0\right)$ & $\left(s_{6}^{7}, 0\right)$ \\
\cline { 2 - 6 } & $A_{2}$ & $\left(s_{5}^{7},-0.083\right)$ & $\left(s_{2}^{7}, 0\right)$ & $\left(s_{6}^{7}, 0\right)$ & $\left(s_{4}^{7}, 0.029\right)$ \\
\cline { 2 - 6 } & $A_{3}$ & $\left(s_{6}^{7}, 0\right)$ & $\left(s_{5}^{7}, 0\right)$ & $\left(s_{5}^{7},-0.083\right)$ & $\left(s_{5}^{7}, 0.028\right)$ \\
\cline { 2 - 6 } & $A_{4}$ & $\left(s_{6}^{7}, 0\right)$ & $\left(s_{6}^{7}, 0\right)$ & $\left(s_{6}^{7}, 0\right)$ & $\left(s_{6}^{7}, 0\right)$ \\
\hline \multirow{5}{*}{$C_{6}$} & $A_{1}$ & $\left(s_{5}^{7},-0.083\right)$ & $\left(s_{2}^{7}, 0\right)$ & $\left(s_{2}^{7},-0.083\right)$ & $\left(s_{3}^{7},-0.056\right)$ \\
\cline { 2 - 6 } & $A_{2}$ & $\left(s_{3}^{7}, 0\right)$ & $\left(s_{5}^{7}, 0\right)$ & $\left(s_{3}^{7}, 0\right)$ & $\left(s_{4}^{7},-0.056\right)$ \\
\cline { 2 - 6 } & $A_{3}$ & $\left(s_{6}^{7}, 0\right)$ & $\left(s_{5}^{7}, 0\right)$ & $\left(s_{6}^{7}, 0\right)$ & $\left(s_{6}^{7},-0.056\right)$ \\
\cline { 2 - 6 } & $A_{4}$ & $\left(s_{3}^{7}, 0\right)$ & $\left(s_{4}^{7}, 0\right)$ & $\left(s_{3}^{7}, 0\right)$ & $\left(s_{3}^{7}, 0.056\right)$ \\
\hline
\end{tabular}

Table 10. The threshold values of each criterion

\begin{tabular}{|l|c|c|c|c|c|l|}
\hline & $C_{1}$ & $C_{2}$ & $C_{3}$ & $C_{4}$ & $C_{5}$ & $C_{6}$ \\
\hline $\begin{array}{l}\text { Thre } \\
\text { shol } \\
\mathrm{d}\end{array}$ & $p=\frac{1}{6}$ & $p=\frac{1}{6}$ & $p=\frac{1}{6}$ & $p=\frac{1}{6}$ & $p=\frac{1}{6}$ & $p=\frac{1}{6}$ \\
$q=\frac{1}{12}$ & & & $q=\frac{1}{12}$ & & \\
\hline
\end{tabular}

Table 11. Preference degree with respect to criterion $C_{1}$

\begin{tabular}{|c|c|c|c|c|}
\hline & $A_{1}$ & $A_{2}$ & $A_{3}$ & $A_{4}$ \\
\hline$A_{1}$ & 0.000 & 0.000 & 1.000 & 1.000 \\
\hline$A_{2}$ & 1.000 & 0.000 & 1.000 & 1.000 \\
\hline$A_{3}$ & 0.000 & 0.000 & 0.000 & 0.000 \\
\hline$A_{4}$ & 0.000 & 0.000 & 1.000 & 0.000 \\
\hline
\end{tabular}

Table 12. Preference degree with respect to criterion $C_{2}$

\begin{tabular}{|c|c|c|c|c|}
\hline & $A_{1}$ & $A_{2}$ & $A_{3}$ & $A_{4}$ \\
\hline$A_{1}$ & 0.000 & 1.000 & 0.000 & 1.000 \\
\hline$A_{2}$ & 0.000 & 0.000 & 0.000 & 0.000 \\
\hline$A_{3}$ & 1.000 & 1.000 & 0.000 & 1.000 \\
\hline$A_{4}$ & 0.000 & 1.000 & 0.000 & 0.000 \\
\hline
\end{tabular}

Table 13. Preference degree with respect to criterion $C_{3}$

\begin{tabular}{|c|c|c|c|c|}
\hline & $A_{1}$ & $A_{2}$ & $A_{3}$ & $A_{4}$ \\
\hline$A_{1}$ & 0.000 & 0.000 & 0.000 & 1.000 \\
\hline$A_{2}$ & 1.000 & 0.000 & 0.500 & 1.000 \\
\hline$A_{3}$ & 0.500 & 0.000 & 0.000 & 1.000 \\
\hline$A_{4}$ & 0.000 & 0.000 & 0.000 & 0.000 \\
\hline
\end{tabular}

Table 14. Preference degree with respect to criterion $C_{4}$

\begin{tabular}{|c|c|c|c|c|}
\hline & $A_{1}$ & $A_{2}$ & $A_{3}$ & $A_{4}$ \\
\hline$A_{1}$ & 0.000 & 0.000 & 0.333 & 0.500 \\
\hline$A_{2}$ & 0.000 & 0.000 & 0.000 & 0.000 \\
\hline$A_{3}$ & 0.000 & 0.000 & 0.000 & 0.000 \\
\hline$A_{4}$ & 0.000 & 0.000 & 0.000 & 0.000 \\
\hline
\end{tabular}

Table 15. Preference degree with respect to criterion $C_{5}$

\begin{tabular}{|c|c|c|c|c|}
\hline & $A_{1}$ & $A_{2}$ & $A_{3}$ & $A_{4}$ \\
\hline$A_{1}$ & 0.000 & 1.000 & 0.500 & 0.000 \\
\hline$A_{2}$ & 0.000 & 0.000 & 0.000 & 0.000 \\
\hline$A_{3}$ & 0.000 & 0.500 & 0.000 & 0.000 \\
\hline$A_{4}$ & 0.000 & 1.000 & 0.500 & 0.000 \\
\hline
\end{tabular}

Table 16. Preference degree with respect to criterion $C_{6}$

\begin{tabular}{|c|c|c|c|c|}
\hline & $A_{1}$ & $A_{2}$ & $A_{3}$ & $A_{4}$ \\
\hline$A_{1}$ & 0.000 & 0.000 & 0.000 & 0.000 \\
\hline$A_{2}$ & 0.000 & 0.000 & 0.000 & 0.000 \\
\hline$A_{3}$ & 1.000 & 0.333 & 0.000 & 0.556 \\
\hline$A_{4}$ & 0.000 & 0.000 & 0.000 & 0.000 \\
\hline
\end{tabular}

Table 17. The overall preference index of each logistics supplier

\begin{tabular}{|c|c|c|c|c|}
\hline & $A_{1}$ & $A_{2}$ & $A_{3}$ & $A_{4}$ \\
\hline$A_{1}$ & 0.000 & 0.409 & 0.383 & 0.737 \\
\hline$A_{2}$ & 0.510 & 0.000 & 0.351 & 0.402 \\
\hline$A_{3}$ & 0.454 & 0.460 & 0.000 & 0.506 \\
\hline$A_{4}$ & 0.036 & 0.409 & 0.356 & 0.000 \\
\hline
\end{tabular}


Table 18. The final result of each logistics supplier

\begin{tabular}{|c|c|c|c|c|c|}
\hline & $\phi^{+}\left(A_{r}\right)$ & $\phi^{-}\left(A_{r}\right)$ & $\phi\left(A_{r}\right)$ & OTI $\left(A_{r}\right)$ & $\left(s_{i}^{5}, \alpha_{i}\right)$ \\
\hline$A_{1}$ & 1.529 & 1.000 & 0.529 & 0.588 & $\left(s_{2}^{5}, 0.088\right)$ \\
\hline$A_{2}$ & 1.263 & 1.278 & -0.015 & 0.498 & $\left(s_{2}^{5},-0.002\right)$ \\
\hline$A_{3}$ & 1.419 & 1.090 & 0.329 & 0.555 & $\left(s_{2}^{5}, 0.055\right)$ \\
\hline$A_{4}$ & 0.801 & 1.645 & -0.843 & 0.359 & $\left(s_{1}^{5}, 0.124\right)$ \\
\hline
\end{tabular}

